Rapid Reviews COVID-19

\title{
Reviews of "Hitting the diagnostic sweet spot: Point-of-care SARS-CoV-2 salivary antigen testing with an off-the-shelf glucometer"
}

\section{Valeria Ghisetti ${ }^{1}$, Gannon C.K. Mak ${ }^{2}$, Bingling Li ${ }^{3}$}

${ }^{1}$ Director, Public Health, Microbiology and Virology, Amedeo di Savoia Hospital, Italy,

2Public Health Laboratory Services Branch, Centre for Health Protection, Department of Health: Hong Kong,

${ }^{3}$ Changchun Institute of Applied Chemistry Chinese Academy of Sciences: Chang Chun Institute of Applied Chemistry Chinese Academy of Sciences, State Key Laboratory of Electroanalytical Chemistry, China

Published on: Oct 30, 2020

DOI: $10.1162 / 2 \mathrm{e} 3983 f 5 . b 93 f 0 a 5 e$

License: Creative Commons Attribution 4.0 International License (CC-BY 4.0). 
To read the original manuscript, click the link above.

Summary of Reviews: This preprint offers a novel diagnostic platform that uses offthe-shelf glucometers to detect SARS-CoV-2 antigens in saliva. The current manuscript offers rigorous validation of the diagnostic technology, but further experiments should be performed before clinical use.

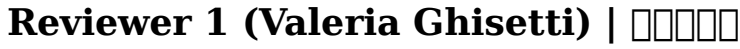

\section{Reviewer 2 (Gannon C.K. Mak)}

$$
\begin{aligned}
& \text { RR:C19 Strength of Evidence Scale Key } \\
& \text { प्रमप = Misleading } \\
& \text { प्र००० = Not Informative } \\
& \text { प्रा पि = Potentially Informative }
\end{aligned}
$$

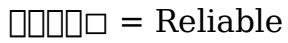

$$
\begin{aligned}
& \text { प्राप्र = Strong }
\end{aligned}
$$

To read the reviews, click the links below. 